\title{
The dilemma and psycho-social challenges of un- intentional infertility in sub-saharan Africa
}

Keywords: infertility, childlessness, ethnic group, children, uterine

Abbreviations: PID, pelvic inflammatory disease; IUA, intrauterine adhesions; PSCs, psycho-social challenges; CARE, comprehensive aids resource emergency

\section{Perspective}

The high rate of infertility and childlessness has been identified as one of the most important health problems in sub-Saharan Africa. ${ }^{1}$ Descendants are indispensable to Nigerian couples. Their future depends on their offspring. Family plays an important role in the experiences of the infertile couple. Children are not only sources of economic support, especially for the woman, but inheritor of all the possession, titles, propagation of family lineage and what most people have spent their entire lives to achieve. It is acknowledged that in most resource poor countries, notwithstanding overpopulation, involuntary childlessness is a significant social and economic burden that deserves attention. Certain Africa adages, such as "omo l'asho" (one's child is one's cloth, indicating a woman without a child is naked), "omo l'ere aiye" (one's child is one's life's sole profit), and "eni omo sin lo bi'mo" (one who is buried by her child or children is one who actually gave birth), reflect value of fertility and why involuntary infertility is an anathema in most African societies. Furthermore, some African communities never refer to a married woman by her name but by the name of her first child such as "Iya Joshua" meaning Joshua's mother or "Iya Ibeji" meaning the mother of twins. Specifically, children often refer to their mother as "Maami" or "Mami" meaning my mother. In Yoruba ethnic group, it is often said that "Iya ni wura", that is mother or motherhood is gold. Even in day-to-day pleasantries between adults, the first statement is never about material possession, but "how are your children?"

Names given to children also emphasize the value of children. Such names as Omolara, Omolade, indicate that one's child is one's family and ones' child is one's crown. The implication is that a woman, specifically, without a child also has no family and a woman without a child is like a king without a crown.

It is then obvious that demonstration of fertility is a key societal and social issue for women and fatherhood is central to a man being identified as a man. When a woman cannot bear children, it tremendously affects her identity, but the pain can extend far beyond her to impact personal relationships. ${ }^{2}$ The desire to have a child is determined by multiple factors, including age, marital status, parity, gender, culture, religious beliefs and the degree of reproductive autonomy and access to contraception in a particular setting. ${ }^{3}$ Stereotypically, women are presumed to desire children and therefore to experience grief when the life goal of motherhood is unrealized, but men, having more diverse life opportunities, have been described as being 'disappointed but not devastated' by the inability to have a child. ${ }^{4}$ The stress of the non-fulfillment of a wish for a child- failure to replicate one's self in one's image, not experiencing pregnancy and not being referred to as a mother- has been associated with

\author{
Volume I Issue I - 2017
}

Bamgboye MAfolabi

Health Environment and Development Foundation, Nigeria

Correspondence: Bamgboye M Afolabi, Health Environment and Development Foundation, 34 Montgomery Road,Yaba, Lagos, Nigeria, Email bmafolabi@gmail.com

Received: July 05, 2017 | Published: July 17, 2017

emotional squeal such as anger, depression, anxiety, marital problems and feelings of worthlessness. It also adds a religious dimension and undertone to the thorny problem of infertility. Partners may become more anxious to conceive, ironically increasing sexual dysfunction and social isolation. Marital discord often develops in infertile couples, especially when they are under pressure to make medical decisions. Couples experience stigma, sense of loss, and diminished self-esteem in the setting of their infertility. ${ }^{5}$

Infertility in Africa is attributable to infection-STDs, post-abortal and puerperal sepsis, pelvic inflammatory disease (PID) and uterine tuberculosis. It is clinically associated also with fibroids, intrauterine adhesions (IUA), septate uterus, endometriosis and uterine atresia, among others. However, cultural belief system concerning causes of infertility, and failure of pre-IVF orthodox methods of treatment goaded many couples to seek solution from traditional and faith healers which often lead to a more devastating outcome and waste of hard-earned resources.

Most women and couples first patronize traditional and faith healers so solve infertility before consulting orthodox health practitioners. ${ }^{6}$ Traditional healers believed that being bewitched or being cursed can lead to infertility. Both traditional and faith healers threat infertility by sacrifices, prayer and fasting, and timing of intercourse to coincide with the fertile period. ${ }^{7}$

Infertility is a major burden not only of public health importance but also of individual and married couple's concern and source of stress in Nigeria and many developing nations.

Infertility is of main concern to all concerned because of its high prevalence, and especially due to its serious social implications. ${ }^{8}$ It is a key source of distress and frustration for men and women and medical practitioners as well. It causes great worry, anxiety, disheartening, desperation and sorrow for many women, men and couples in Africa, especially women. ${ }^{9}$ It is also the root cause of marital disharmony, which often leads to divorce.

The knowledge of infertility and fertility determines, to a large extent, the health seeking behavior of sufferers. There seems to be a lot of ignorance, misinformation and superstitious beliefs and myths about infertility, its causes and how to best manage it. A lot of the difficulties in infertility management arise from delay in presentation. Some of this delay is due to lack of knowledge and lack of explicit information. The fertility IQ 2012 healthcare provider survey revealed 
that most patients were aware of general fertility information but were less aware of specific details. ${ }^{10}$ When men and women become aware of all the issues surrounding fertility and infertility they would be more likely able to properly address this problem.

Although there is a plethora of literature demonstrating the psychological and social distress which occurs when infertility is discovered yet few studies have examined the effects of infertility on women's lives in developing countries, especially Nigeria.

Infertility has social, economic and personal effects, which go beyond childlessness and women bear the major brunt of the burden. ${ }^{11}$ There is urgent need for a comprehensive sexual and reproductive healthcare initiative infertility prevention and management as well as related maternal and child health, safe abortions and family planning. The provision of low cost assisted reproduction for couples in poorly resourced countries needs to be addressed.

Infertility undoubtedly has an emotional influence and the relative effects of infertility management on quality of life deserve significant attention. ${ }^{12-14}$ There are also obvious gender dynamics and veiled social burden of marginalization, discrimination and stigmatization against women (and men) who have never had a child. In most recent times, stigmatization was openly identified with HIV/AIDS when, in 1990, the Ryan White Comprehensive AIDS Resource Emergency (CARE) Act was promulgated to protect HIV/AIDS patients from discrimination and stigmatization. However, unlike the case of Ryan White's parents whose experience of stigmatization brought national attention to all aspects of the illness, those with infertility have no public face or public voice to speak for them due mainly to selfstigmatization which is probably part of the psycho-social challenges (PSCs) an infertile woman faces, much more than an infertile man. Other aspects of PSCs, especially from the woman's perspective, are her being un-noticeably isolated from family member, husband courting another woman during matrimony, negative attitude of not only husband but of husband's family, fear, insecurity, depression, distress, loneliness, embarrassment, physical and/or mental abuse, anger and disappointments

\section{Conclusion}

Infertility is a major public health problem in sub-Saharan Africa which is not addressed aggressively. A married African woman nowadays wants to have one of two children to consummate the marriage and demonstration of fertility is a key societal and social issue for women and fatherhood is central to a man being identified as a man. Infertility is associated with silent stigmatization with other psychosocial challenges. More in-depth quantitative, qualitative and mixed studies would be beneficial to elucidate the exact psycho-social challenges that infertile sub-Saharan African women are facing and the degree to which these impact on their health and quality of life.

\section{Acknowledgements}

None.

\section{Conflict of interest}

The author declares no conflict of interest.

\section{References}

1. Leke RJ, Oduma JA, Bassol-Mayagoitia S, et al. Regional and geographical variations in infertility: effects of environmental, cultural, and socioeconomic factors. Environ Health Perspect. 1993;101(Suppl 2):73-80.

2. Getz L. The Impact of Infertility. Social Work Today. 2014;12(6):30.

3. Hadley R, Hanley T. Involuntarily childless men and the desire for fatherhood. Journal of Reproductive and Infant Psychology. 2011;29(1):56-68.

4. Greil AL. Infertility and psychological distress: a critical review of the literature. Soc Sci Med. 1997;45(11):1679-1704.

5. Nachtigall RD, Becker G, Wozny M. The Effects of gender-specific diagnosis on men's and women's response to infertility. Fertil Steril. 1992;57(1):113-121.

6. Gerrits T. Social and cultural aspects of infertility in Mozambique. Patient Educ Couns. 1997;31(1):39-48.

7. Obisesan KA, Adeyemo AA. Infertility and other fertility related issues in the practice of traditional healers and Christian religious healers in south western Nigeria. Afr J Med Med Sci. 1998;27(1-2):51-55.

8. Araoye MO. Epidemiology of infertility: social problems of the infertile couples. West Afr J Med. 2003;22(2):190-196.

9. Ebere AB. The Problem of Infertility in Africa. The Human Life Review. 2013;39(2):10

10. Matetakuta SN. Our Own Gift: Infertility Is Not Just a Problem in the West. New Internationalist. 1998;(303).

11. Sharma S, Mittal S, Aggarwal P. Management of infertility in low resource countries. BJOG. 2009;116 (Suppl 1):77-83.

12. Letourneau JM, Ebbel EE, Katz PP, et al. Pretreatment fertility counseling and fertility preservation improve quality of life in reproductive age women with cancer. Cancer. 2012;118(6):1710-1717.

13. Greil AL, McQuillan J, Lowry M, et al. Infertility treatment and fertilityspecific distress: A longitudinal analysis of a population-based sample of U.S. women. Soc Sci Med. 2011;73(1):87-94.

14. Wilkins KM, Warnock JK, Serrano E. Depressive symptoms related to infertility and infertility treatments. Psychiatr Clin North Am. 2010;33(2):309-321. 